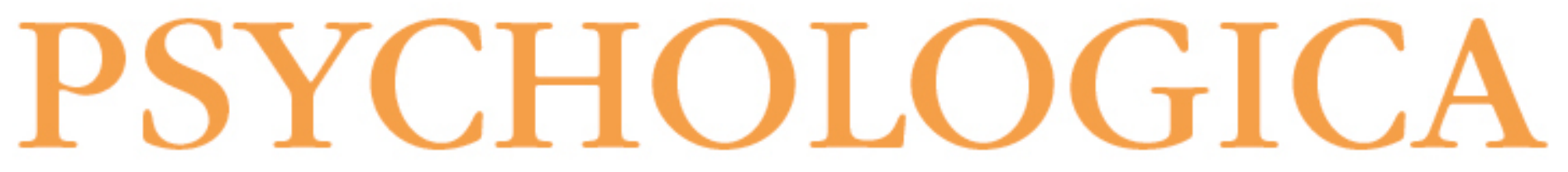

\title{
Estudo psicométrico preliminar da Mental Health Continuum - Short Form - for youth numa amostra de adolescentes portugueses
}
Autor(es):
Matos, Ana Paula; André, Raquel Simão; Cherpe, Sónia; Rodrigues, Daniela; Figueira, Célia; Pinto, Alexandra Marques

Publicado por: Imprensa da Universidade de Coimbra

URL persistente:

URI:http://hdl.handle.net/10316.2/5530

DOI:

DOI:http://dx.doi.org/10.14195/1647-8606_53_7

Accessed : $\quad$ 26-Apr-2023 15:50:12

A navegação consulta e descarregamento dos títulos inseridos nas Bibliotecas Digitais UC Digitalis, UC Pombalina e UC Impactum, pressupõem a aceitação plena e sem reservas dos Termos e Condições de Uso destas Bibliotecas Digitais, disponíveis em https://digitalis.uc.pt/pt-pt/termos.

Conforme exposto nos referidos Termos e Condições de Uso, o descarregamento de títulos de acesso restrito requer uma licença válida de autorização devendo o utilizador aceder ao(s) documento(s) a partir de um endereço de IP da instituição detentora da supramencionada licença.

Ao utilizador é apenas permitido o descarregamento para uso pessoal, pelo que o emprego do(s) título(s) descarregado(s) para outro fim, designadamente comercial, carece de autorização do respetivo autor ou editor da obra.

Na medida em que todas as obras da UC Digitalis se encontram protegidas pelo Código do Direito de Autor e Direitos Conexos e demais legislação aplicável, toda a cópia, parcial ou total, deste documento, nos casos em que é legalmente admitida, deverá conter ou fazer-se acompanhar por este aviso.
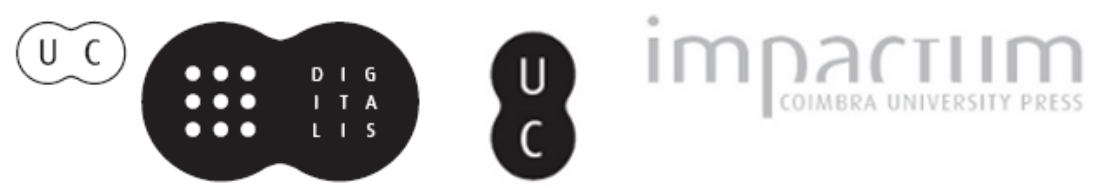
NÚMERO 53

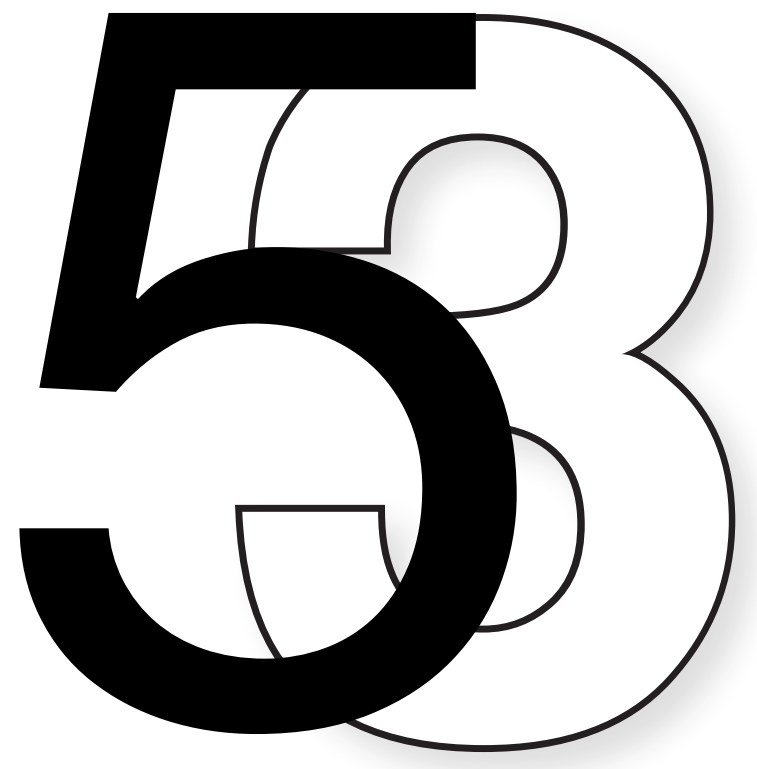

IMPRENSA DA UNIVERSIDADE DE COIMBRA

FACULDADE DE PSICOLOGIA E DE CIÊNCIAS DA EDUCAÇÃO DA UNIVERSIDADE DE COIMBRA 


\section{Estudo Psicométrico preliminar da Mental Health Continuum - Short Form - for youth numa amostra de adolescentes portugueses}

Ana Paula Matos', Raquel Simão André², Sónia Cherpe³, Daniela Rodrigues 4 , Célia Figueira5 \& Alexandra Marques Pinto ${ }^{6}$

A definição e avaliação da saúde mental pressupõem não só a ausência de doença mental, como, também, a existência de bem-estar subjectivo (WHO, 2004). Keyes (2002) propôs uma escala de auto-resposta, a Mental Health Continuum - Short Form - for youth (MHC-SF), com o objectivo de avaliar num continuum a saúde mental e de identificar diagnósticos categoriais (flourishing, saúde mental moderada e languishing). Neste estudo, traduzimos e adaptámos a referida escala para uma amostra de adolescentes Portugueses. Foi desenvolvido um estudo psicométrico da MHC-SF através da exploração da sua estrutura factorial, da análise da consistência interna, da validade convergente e divergente. Esta escala revelou boas propriedades psicométricas, parecendo indicada para detectar categorias de saúde mental nos adolescentes. Poderá ainda ser utilizada na identificação de dimensões do bem-estar (psicológico, emocional e social) as quais são importantes na prevenção e tratamento da doença mental, assim como na protecção e promoção da saúde mental.

PALAVRAS-CHAVE: Estudo Psicométrico, Estados de Saúde Mental, Bem-estar Subjectivo, Doença Mental, Promoção da Saúde Mental.

\footnotetext{
1 Professora Associada da Faculdade de Psicologia e Ciências da Educação da Universidade de Coimbra - apmatosfpce.uc.pt

2 Mestre em Psicologia Clínica e da Saúde, subárea de especialização em intervenções cognitivo - comportamentais em perturbações psicológicas e da saúde.

3 Investigadora no Centro de Investigação do Núcleo de Estudos e Intervenção Cognitivo-Comportamenta da FPCE da Universidade de Coimbra; Psicóloga Clínica na Associação de Apoio a Doentes Depressivos e Bipolares.

4 Mestre em Psicologia Clínica e da Saúde, subárea de especialização em intervenções cognitivo - comportamentais em perturbações psicológicas e da saúde.

5 Doutoranda da Faculdade de Psicologia da Universidade de Lisboa.

6 Professora Auxiliar da Faculdade de Psicologia da Universidade de Lisboa.
} 


\section{Introdução}

\subsection{Enquadramento teórico e evolução do conceito de saúde mental}

Até muito recentemente, equiparava-se a saúde e o bem-estar de crianças, adolescentes e adultos à ausência de doença (ou deficiência) e o conceito de saúde mental permanecia indefinido e não mensurável (Keyes, 2007). Estas dificuldades têm sido progressivamente ultrapassadas. Além disso, a nível científico, o interesse pelo estudo das emoções positivas e do bem-estar subjectivo tem vindo a aumentar significativamente (Duckworth, Steen \& Seligman, 2005; Seligman \& Csikszentmihalyi, 2000).

À semelhança da doença, a saúde mental tem sido conceptualizada de acordo com o conceito de 'síndrome', isto é, um conjunto de sintomas, neste caso, de bem-estar subjectivo (Keyes, 2002, 2003, 2006, 2007; Keyes, Shmotkin e Ryff, 2002).

Corey Keyes é um dos grandes impulsionadores da investigação no âmbito da avaliação e promoção da saúde mental. Segundo este autor (2010), o conceito de saúde mental pode ser conceptualizado num continnum: num extremo, situa-se o estado de languishing, definido como um estado de saúde mental no qual o indivíduo considera que não está bem emocionalmente e que não tem um bom funcionamento; seguindo-se o estado de saúde mental moderada; e no outro extremo, o estado de flourishing, que se caracteriza por uma combinação de bem-estar emocional e funcionamento positivo. Para Keyes $(2005 a, 2006)$ a saúde mental completa é concebida como um estado no qual os indivíduos estão em flourishing e livres de psicopatologia, com niveis altos de bem-estar (emocional, psicológico e social).

Vários autores (Keyes, 2003, 2005a, 2007, 2009, 2010; Suldo \& Shaffer, 2008) têm encontrado apoio para um modelo de "duplo contínuo", no qual se considera a saúde mental e a doença mental não como extremos de uma dimensão bipolar, mas como duas dimensões unipolares diferentes, mas correlacionadas.

\subsection{Bem-estar subjectivo como indicador de saúde mental}

Segundo Keyes (2002), a saúde mental pode ser medida através do bem-estar subjectivo, para o qual têm sido identificadas três dimensões - emocional, social e psicologica - que se agrupam, teórica e empiricamente, em dois conjuntos de sintomas: bem-estar emocional e funcionamento adaptativo.

A dimensão bem-estar emocional é constituida por sintomas que reflectem a 'vitalidade emocional' (emoções positivas avaliadas pelo grau de felicidade, inte- 
resse e satisfação pela vida). As dimensões bem-estar psicológico e bem-estar social incluem os sintomas de funcionamento positivo. Uma pessoa com saúde mental, a nível psicológico, auto-avalia-se positivamente e aceita-se como é, está num processo continuum de desenvolvimento pessoal, tem objectivos, percepção de sentido e direcção na vida, tem relacionamentos íntimos e calorosos, lida com o contexto envolvente de modo a satisfazer necessidades e tem um grau significativo de auto-determinação. A pessoa mentalmente saudável, a nível social, percepciona a sociedade como significativa para si, considera que esta permite o seu desenvolvimento pessoal, percebe-se como aceite, integrada e entende que contribui para a evolução dessa mesma sociedade.

Como as três dimensões de bem-estar, apesar de serem independentes se relacionam entre si, Keyes $(2002,2006,2009)$ propôs que estas fossem medidas com um único instrumento que avaliaria a existência de saúde mental.

\section{3 $O$ continuum de saúde mental}

Em 2009, Keyes desenvolveu a Mental Health Continuum-Short Form (MHC - SF) - for youth, a qual contempla a saúde mental num continnum e avalia estados de saúde mental, estimados a partir do grau de bem-estar - emocional, social e psicológico - percebido pelos adolescentes.

Num estudo efectuado com 1200 adolescentes, dos 12 aos 18 anos de idade, Keyes (2009), através de análises factoriais confirmatórias, obteve a existência de três factores latentes - bem-estar emocional, bem-estar social e bem-estar psicológico - os quais apresentavam uma boa consistência interna.

A MHC - SF é uma versão abreviada de uma escala de bem-estar subjectivo utilizada previamente em adultos. É um instrumento de auto-resposta e pode ser aplicado a adolescentes com idades compreendidas entre os 12 e os 18 anos.

O adolescente é questionado sobre quantas vezes, durante o último mês, se sentiu de determinada forma. As possibilidades de resposta, cotadas de o a 5 , são as seguintes: nunca (o); uma ou duas vezes (1); cerca de uma ou duas vezes por semana (2); cerca de duas ou três vezes por semana (3); quase todos os dias (4); todos os dias (5).

A MHC - SF é constituída por 14 itens, dos quais três dizem respeito ao bem-estar emocional (1.felicidade, 2.interesse e 3.satisfação com a vida), cinco ao bem-estar social (4.contribuição social, 5.integração na sociedade, 6.actualização e crescimento social, 7.aceitação social e 8.coerência social) e seis ao bem-estar psicológico (9.auto-aceitação, 10.domínio sobre o ambiente, 11.relações positivas com os outros, 12.crescimento pessoal, 13.automonia e 14.propósito na vida). 
Segundo Keyes (2007, 2009), o adolescente encontra-se num estado de flourishing se pontuar com 4 (quase todos os dias) ou 5 (todos os dias) em pelo menos um dos três itens de bem-estar emocional e em pelo menos seis dos onze itens de funcionamento positivo (bem-estar social e psicológico). A identificação de um estado de languishing é efectuada quando o adolescente pontua com o (nunca) ou 1 (uma ou duas vezes) em pelo menos um dos três itens de sintomas de bem-estar emocional e em pelo menos seis dos onze itens de funcionamento positivo. Um estado de saúde mental moderada significa que o adolescente pontua com 2 (cerca de uma ou duas vezes por semana) ou 3 (cerca de duas ou três vezes por semana) em pelo menos um dos três itens de bem-estar emocional e em pelo menos seis dos onze itens de funcionamento positivo.

Os objectivos principais desta investigação foram traduzir, adaptar e efectuar o estudo psicométrico da MHC-SF.

\section{Metodologia:}

\subsection{Caracterização da Amostra}

Para atingir os objectivos mencionados, procedeu-se à recolha de uma amostra de adolescentes Portugueses, da população geral, com idades compreendidas entre os 12 e os 16 anos.

A amostra recolhida ficou constituída por 905 adolescentes, dos quais 357 são do sexo masculino (39.4\%) e 548 do sexo feminino (60.6\%). A média de idades da amostra é de 13.87 anos ( $D P=1.417$ ), não havendo diferenças estatisticamente significativas entre os géneros quanto à idade $[M=13.94$; $D P=1.435$ vs $M=13.76$; $D P$ $=1.383 ; t=-1.911 ; p=.056]$.

No entanto, verificam-se diferenças significativas relativamente ao número de indivíduos que compõem cada um dos níveis etários da amostra $\left[\chi^{2}=23.680\right.$; $p=.000]$. Existe uma percentagem maior de adolescentes com 12 anos (24.8\%), seguindo-se os adolescentes com 15 anos (22.4\%), com 14 (19.4\%), com 13 (17.6\%) e, por fim, com 16 anos (15.8\%).

A média de anos de escolaridade é de 8.08 anos ( $D P=1.366$ ) e encontram-se diferenças estatisticamente significativas entre os géneros $[M=8.17$; $D P=1.410$ vs $M=7.96 ; D P=1.286 ; t=2.245 ; p=.025]$, apresentando as raparigas valores ligeiramente mais elevados. 
Os adolescentes da amostra frequentam escolas do meio urbano das zonas centro e norte do país. Relativamente ao estatuto sócio-económico ${ }^{7}, 55.7 \%$ pertence a um nível baixo e $44.3 \%$ a um nível médio/alto ${ }^{8}$.

\subsection{Procedimentos}

Procedimento de recolha da amostra. Após ter sido aprovado o estudo pelas direcções das escolas, os encarregados de educação autorizavam a participação dos seus educandos na investigação assinando um consentimento informado. A aplicação do protocolo de avaliação foi realizada colectivamente na sala de aula, tendo sido garantidos o anonimato e a confidencialidade das respostas e esclarecidas possíveis dúvidas.

Procedimento estatístico. Os procedimentos estatísticos foram efectuados através do programa Statistical Package for Social Sciences (SPSS), versão 17.0 para o Windows. Foram utilizadas estatísticas descritivas como frequências, médias e desvios-padrão. Para a estatística inferencial recorreu-se a testes $t$-student para amostras independentes, análises de variância de uma via, testes de qui-quadrado e correlações de Pearson. Para o estudo da análise factorial da MHC-SF utilizou-se o método de componentes principais.

\subsection{Instrumentos}

O protocolo de avaliação é composto por um questionário sócio-demográfico, com várias questões para a recolha deste tipo de informação, e uma bateria de questionários de auto-resposta: Mental Health Continuum - Short Form - for youth (MHC-SF; Keyes, 2009), Children's Depression Inventory (CDI; Kovacs, 1992), Children's Attribucional Style Questionnaire (CASQ; Seligman, Peterson, Kaslow, Tanenbaum, Alloy \& Abramsom, 1984), Multidiensional Anxiety Scale for Children (MASC; March, Parker, Sullivam, Stallings \& Conners, 1997), Child Behavior Cheklist (CBCL; Achenbach, 1991), kidscreen27 (The KIDSCREEN Group European, 2006; traduzido e adaptado por Matos, Gaspar \& Equipa do Aventura Social e Saúde, 2006) e Satisfaction With Life Scale (SWLS; Diener, Emmons, Larsen \& Griffin, 1984; traduzida e adaptada por Neto, 1993).

7 Utilizou-se o sistema de classificação de Simões (1994) que sugere as seguintes categorias: baixo, médio e alto.

8 Neste estudo procedeu-se a um reagrupamento dos níveis socioeconómicos, tendo sido criado um nível 'médio/alto', uma vez que a condição 'nível socioeconómico alto' continha muito poucos sujeitos comparativamente com as condições 'médio' e 'baixo'. 


\section{Resultados}

3.1 Características da distribuição das pontuações da MHC-SF- simetria e curtose Através da leitura do quadro 1, verifica-se que no factor bem-estar emocional as pontuações apresentam uma distribuição assimétrica negativa (enviesada à direita - predominância de valores mais altos) e leptocúrtica (menos achatada valores mais concentrados). Por outro lado, a distribuição dos resultados obtidos nos factores bem-estar social e bem-estar psicológico apresenta uma ligeira assimetria (negativa) e achatamento (mesocúrticas - valores mais dispersos). No entanto, para o tratamento de dados, será assumida uma distribuição normal para as pontuações obtidas nestes factores, dado o número elevado de sujeitos que constituem a amostra.

Quadro 1 - Análise descritiva dos factores da MHC-SF

\begin{tabular}{lcc}
\cline { 2 - 3 } & Assimetria & Curtose \\
\hline Bem-estar emocional & -1.180 & 1.297 \\
\hline Bem-estar social & -.021 & -.684 \\
\hline Bem-estar psicológico & -.379 & -.373 \\
\hline
\end{tabular}

A análise das médias das frequências das respostas dadas aos vários itens da MHC-SF revela que a dimensão bem-estar social é aquela que apresenta médias de frequências mais baixas, situando-se a maior parte delas na resposta de "uma a duas vezes por semana" (é o caso dos itens da contribuição social, da actualização social e da coerência social) e as restantes na resposta "duas a três vezes por semana” (é o caso dos itens da integração social e da aceitação social). A dimensão bem-estar psicológico apresenta valores intermédios entre o bemestar social e o bem-estar emocional, sendo que todos os itens se encontram na resposta "duas a três vezes por semana". O bem-estar emocional é a dimensão que apresenta valores mais elevados, situando-se todos os itens que a compõem na resposta "quase todos os dias" (Quadro 2). 
Quadro 2 - Médias das frequências das respostas ${ }^{9}$, relativas ao último mês, para cada item da MHC-SF

\begin{tabular}{|c|c|c|c|c|c|}
\hline $\begin{array}{l}\text { Bem-estar } \\
\text { emocional }\end{array}$ & $M$ & $\begin{array}{l}\text { Bem-estar } \\
\text { psicológico }\end{array}$ & $M$ & $\begin{array}{l}\text { Bem-estar } \\
\text { social }\end{array}$ & $M$ \\
\hline $\begin{array}{l}\text { item } 2 . \\
\text { Interesse }\end{array}$ & 3.93 & $\begin{array}{l}\text { item } 14 . \\
\text { Propósito na vida }\end{array}$ & 3.47 & $\begin{array}{l}\text { item } 7 . \\
\text { Aceitação }\end{array}$ & 2.79 \\
\hline $\begin{array}{l}\text { item } 1 . \\
\text { Felicidade }\end{array}$ & 3.81 & $\begin{array}{l}\text { item } 10 . \\
\text { Ambiente }\end{array}$ & 3.24 & $\begin{array}{l}\text { item } 5 . \\
\text { Integração }\end{array}$ & 2.73 \\
\hline \multirow[t]{4}{*}{$\begin{array}{l}\text { item } 3 . \\
\text { Satisfação }\end{array}$} & 3.65 & $\begin{array}{l}\text { item } 12 . \\
\text { Crescimento Pessoal }\end{array}$ & 3.22 & $\begin{array}{l}\text { item } 4 . \\
\text { Contribuição }\end{array}$ & 2.40 \\
\hline & & $\begin{array}{l}\text { item } 13 . \\
\text { Autonomia }\end{array}$ & 3.20 & $\begin{array}{l}\text { item } 8 . \\
\text { Coerência }\end{array}$ & 2.20 \\
\hline & & $\begin{array}{l}\text { item } 9 . \\
\text { Auto-aceitação }\end{array}$ & 3.10 & $\begin{array}{l}\text { item } 6 . \\
\text { Actualização e } \\
\text { Crescimento }\end{array}$ & 2.16 \\
\hline & & $\begin{array}{l}\text { item } 11 . \\
\text { Relações positivas }\end{array}$ & 2.69 & & \\
\hline
\end{tabular}

4.2. Características da distribuição das pontuações da MHC-SF, em função do género Através da leitura do quadro 3, verificamos que o sexo masculino apresenta médias superiores em todas as dimensões do bem-estar subjectivo comparativamente ao sexo feminino.

Quadro 3- Pontuações médias e desvios-padrão dos factores da MHC-SF (da amostra total e em função do género)

\begin{tabular}{|c|c|c|c|c|c|}
\hline & \multirow[b]{2}{*}{ Amostra total } & \multicolumn{2}{|c|}{ Género } & & \\
\hline & & Masculino & Feminino & & \\
\hline & $M(D P)$ & $M(D P)$ & $M(D P)$ & $\mathrm{t}$ & $\mathrm{p}$ \\
\hline Bem-estar emocional & 11.39 (2.93) & $11.76(2.70)$ & $11.16(3.05)$ & 2.93 & .004 \\
\hline Bem-estar social & $12.29(5.94)$ & $13.48(5.50)$ & $11.52(5.90)$ & 4.75 & .000 \\
\hline Bem-estar psicológico & $18.93(6.44)$ & $19.68(6.13)$ & $18.45(6.59)$ & 2.74 & .006 \\
\hline
\end{tabular}

\subsection{Características da distribuição das pontuações da MHC-SF, em função da idade} Existem ainda diferenças significativas entre os níveis etários apenas para o bem-estar emocional $[F(4,831)=2.90 ; p=.021)$. Testes post-hoc de Tukey revelam que estas diferenças ocorrem entre os 12 e os 16 anos $(M=11.78$ vs $M=10.84 ; p=.031)$, apresentando os adolescentes de doze anos valores mais elevados (Quadro 4).

9 Possibilidades de resposta: Nunca (0); 1-2 vezes (1); 1-2 vezes/semana (2); 2-3 vezes/semana (3); quase todos os dias (4); todos os dias (5). 
Quadro 4 - Pontuações médias e desvios-padrão dos factores da MHC-SF em função da idade

138

\begin{tabular}{lccccc} 
& \multicolumn{5}{c}{ Idades } \\
& $\mathbf{1 2}$ & $\mathbf{1 3}$ & $\mathbf{1 4}$ & $\mathbf{1 5}$ & $\mathbf{1 6}$ \\
& $\mathrm{M}(\mathrm{DP})$ & $\mathrm{M}(\mathrm{DP})$ & $\mathrm{M}(\mathrm{DP})$ & $\mathrm{M}(\mathrm{DP})$ & $\mathrm{M}(\mathrm{DP})$ \\
Bem-estar emocional & 11.78 & 11.52 & 11.62 & 11.10 & 10.84 \\
& $(3.04)$ & $(3.06)$ & $(2.53)$ & $(2.66)$ & $(3.29)$ \\
Bem-estar social & 12.89 & 12.43 & 12.20 & 12,30 & $11.33(5.77)$ \\
Bem-estar psicológico & $(6.01)$ & $(6.20)$ & $(6.16)$ & $(5.51)$ & \\
& 19.60 & 19.01 & 18.92 & 18.40 & 18.70 \\
& $(6.40)$ & $(6.51)$ & $(6.60)$ & $(6.01)$ & $(6.77)$ \\
& $\mathrm{N}=198$ & $\mathrm{~N}=145$ & $\mathrm{~N}=164$ & $\mathrm{~N}=192$ & $\mathrm{~N}=137$
\end{tabular}

Através de uma correlação de Pearson, obteve-se uma associação fraca entre a auto-percepção de saúde mental (total da MHC-SF) e a idade, o que significa que, entre os 12 e os 16 anos de idade, a saúde mental tende a diminuir ( $r=-.088 ; p=.011)$.

A partir dos resultados obtidos na amostra geral (dos 12 aos 16 anos), verifica-se que 138 (16.4\%) dos adolescentes estão em languishing, 327 (38.9\%) encontram-se num estado de saúde mental moderada e 376 (44.7\%) estão em flourishing. Salienta-se que se a amostra for dividida em dois grupos, um dos 12 aos 14 anos (a frequentarem o $2^{\circ}$ e $3^{\circ}$ ciclos) e outro dos 15 aos 16 anos (a frequentarem o ensino secundário), se verifica, novamente, um decréscimo de $3.3 \%$, no estado de flourishing, do primeiro para o segundo grupo (Quadro 5).

Quadro 5 - Análise descritiva dos estados de saúde mental em função dos patamares etários

\begin{tabular}{lcc}
\hline & \multicolumn{2}{c}{ Idade } \\
\cline { 2 - 3 } Estados de Saúde Mental & $\mathbf{1 2 - 1 4}$ & $15-16$ \\
& $\mathbf{N}(\%)$ & $\mathbf{N}(\%)$ \\
\hline languishing & $84(16.4 \%)$ & $54(16.4 \%)$ \\
saúde mental moderada & $192(37.6 \%)$ & $135(40.9 \%)$ \\
flourishing & $235(46 \%)$ & $141(42.7 \%)$ \\
\hline & $\mathrm{N}=511$ & $\mathrm{~N}=330$ \\
\hline
\end{tabular}

\subsection{Resultados relativos à validade - solução factorial}

Com base na análise factorial exploratória, determinaram-se os factores que compõem a estrutura factorial da MHC-SF para a população Portuguesa, tal como os itens que Ihes estão associados. Utilizou-se o método de extracção de componentes principais, seguido da rotação Varimax dos factores, no intuito de se obter uma solução factorial mais clara e objectiva, maximizando assim os pesos factoriais dos itens. Seguindo as orientações de vários autores (Blunch, 2008; Brown, 2006; 
Hair, Black, Babin, Anderson \& Tatham, 2006), os critérios de determinação dos factores utilizados foram:

1. Critério de Kaiser: factores com valor próprio igual ou superior a 1;

2. Peso factorial dos itens igual ou superior .30;

3. Inexistência de itens com pesos factoriais com alguma relevância (>.30) em mais do que um factor. Se isso acontecer e se a diferença entre eles não for significativa (cross-loadings $\leq .10$ ) sugere-se que o item seja eliminado;

4. A percentagem de variância explicada pelos factores retidos deve ser no mínimo de pelo menos $40 \%$;

5. A consistência interna, medida pelo alpha de Cronbach, do factor deve ser igual ou superior a .70;

6. A consistência interna do factor não deve aumentar no caso de um item ser eliminado;

7. Só devem ser retidos os factores com pelo menos 3 itens.

Verificou-se que foram cumpridos os seguintes pressupostos: (i) a análise da matriz de correlações revelou a presença de muitos coeficientes iguais e superiores a .30; (ii) o valor do índice Kaiser-Meyer-Olkin encontrado de .910, excedeu o valor mínimo recomendado $(K M O \geq .60)$ e o teste de esfericidade de Bartlett revelou significância estatística $(p=.000)$.

Assim, na análise dos componentes principais, a solução factorial foi submetida a uma rotação Varimax, a qual revelou a presença de três componentes com eigenvalues superiores a 1, nomeadamente de 6.082 para o factor bem-estar emocional, de 1.373 para o factor bem-estar social e de 1.152 para o factor bem-estar psicológico. Estes três factores são responsáveis pela explicação de $61.476 \%$ da variância da escala, sendo que cada um explica, respectivamente, 43.439\%, 9.810\% e $8.227 \%$ da variância (Quadro 6).

Os resultados das comunalidades indicam que todas atingiram valores bastantes aceitáveis, acima de .50 (Hair et al., 2006), deduzindo-se que uma boa parte da variância dos resultados de cada item é explicada pela solução factorial encontrada. A única excepção é o item 5, cujo valor indica que a solução factorial explica apenas $32.4 \%$ da variância do item 5 (Quadro 6).

No que diz respeito aos pesos dos itens que constituem os factores, verificámos que todos os itens apresentavam pesos factoriais aceitáveis nos respectivos factores, variando entre .470 e .842 no factor bem-estar emocional, entre .449 e .832 no factor bem-estar social e entre .436 e .760 no factor bem-estar psicológico (Quadro 6). 
No entanto, encontrámos a existência de um cross-loading no item 9. Especificamente, este item satura com o mesmo valor (.436) nos factores 2 e 3 e, ainda, satura no factor 1 (.427) com uma diferença entre eles de apenas .oog.

Assim, podemos concluir que o factor bem-estar emocional é constituido pelos itens 1, 2, 3, 10 e 14; o factor bem-estar social pelos itens 4, 5, 6, 7 e 8; e o factor bem-estar psicológico pelos itens 9, 11, 12 e 13 .

Quadro 6 - Resultados da Análise Factorial Exploratória - Método dos Componentes Principais com Rotação Varimax

\begin{tabular}{|c|c|c|c|c|}
\hline \multirow[b]{2}{*}{ Itens da MHC-SF e respectivo $\mathrm{n}^{\circ}$} & \multicolumn{3}{|c|}{ Componentes Principais } & \multirow[b]{2}{*}{$\begin{array}{l}\text { Comunali- } \\
\text { dades }\end{array}$} \\
\hline & Factor 1 & Factor 2 & Factor 3 & \\
\hline \multicolumn{5}{|l|}{ Factor bem-estar emocional } \\
\hline Satisfeito (3) & .842 & & & .750 \\
\hline Interessado pela vida (2) & .832 & & & .752 \\
\hline Feliz (1) & .791 & & & .695 \\
\hline $\begin{array}{l}\text { Que a tua vida tem uma direcção ou } \\
\text { significado (14) }\end{array}$ & .556 & & .482 & .594 \\
\hline $\begin{array}{l}\text { Que geriste bem as responsabili- } \\
\text { dades da tua vida diária (10) }\end{array}$ & .470 & & .416 & .498 \\
\hline \multicolumn{5}{|l|}{ Factor bem-estar social } \\
\hline $\begin{array}{l}\text { Que a forma como a nossa sociedade } \\
\text { funciona te faz sentido (8) }\end{array}$ & & .836 & & .739 \\
\hline $\begin{array}{l}\text { Que a nossa sociedade se está a tor- } \\
\text { nar num lugar melhor para as pessoas } \\
\text { como tu (6) }\end{array}$ & & .835 & & .741 \\
\hline $\begin{array}{l}\text { Que as pessoas são essencialmente } \\
\text { boas ( } 7)\end{array}$ & & .751 & & .644 \\
\hline $\begin{array}{l}\text { Que tinhas alguma coisa importante } \\
\text { para contribuir para a sociedade (4) }\end{array}$ & & .523 & .360 & .443 \\
\hline Que pertencias a uma comunidade (5) & & .449 & & .324 \\
\hline \multicolumn{5}{|l|}{ Factor bem-estar psicológico } \\
\hline $\begin{array}{l}\text { Que tiveste experiências que te per- } \\
\text { mitiram crescer e tornares-te numa } \\
\text { pessoa melhor (12) }\end{array}$ & & & .760 & .652 \\
\hline $\begin{array}{l}\text { Que tiveste relações calorosas e de con- } \\
\text { fianças com pessoas da tua idade (11) }\end{array}$ & & & .738 & .562 \\
\hline $\begin{array}{l}\text { Confiante para pensar e exprimir as } \\
\text { tuas próprias ideias e opiniões (13) }\end{array}$ & .373 & & .676 & .649 \\
\hline $\begin{array}{l}\text { Que gostavas da maior parte das car- } \\
\text { acterísticas da tua personalidade (9) }\end{array}$ & .427 & .436 & .436 & .563 \\
\hline
\end{tabular}




\subsection{Consistência interna}

O alpha de Cronbach para o total da MHC-SF é de .90, o que traduz uma consistência interna muito boa. Também a nível dos factores, estes valores são bastante satisfatórios: bem-estar emocional $(a=.847)$, bem-estar social $(a=.803)$ e bem-estar psicológico $(a=.829)$ (Quadro 7).

Quadro 7 - Consistência interna (alpha de Cronbach) dos factores da MHC-SF

\begin{tabular}{lll}
\hline Factores da MHC-SF & Estrutura Factorial Obtida & $\begin{array}{l}\text { Versão Original } \\
\text { (Keyes, 2009) }\end{array}$ \\
\hline Bem-estar emocional & .85 & .84 \\
Bem-estar social & .80 & .80 \\
Bem-estar psicológico & .83 & .78 \\
\hline
\end{tabular}

As correlações entre os itens e os respectivos factores variam de .44 a .71 (Quadro 8).

Verificámos ainda, para o item 5 , que se este fosse eliminado da escala a consistência interna do factor bem-estar social aumentaria de forma ligeira (.o1) (Quadro 8).

Quadro 8 - Consistência interna dos itens dos factores da MHC-SF

\begin{tabular}{lll}
\hline Itens da MHC-SF & $\begin{array}{l}\text { Correlação } \\
\text { Item-Total do factor }\end{array}$ & $\begin{array}{l}\text { alpha de Cronbach } \\
\text { (se o item for removido) }\end{array}$ \\
\hline Factor bem-estar emocional $(\mathrm{a}=.85)$ & & .79 \\
MHC1 & .71 & .80 \\
MHC2 & .70 & .76 \\
MHC3 & .54 & \\
Factor bem-estar social (a=.80) & & .78 \\
MHC4 & .54 & .81 \\
MHC5 & .45 & .72 \\
MHC6 & .71 & .76 \\
MHC7 & .60 & .74 \\
MHC8 & .65 & \\
Factor bem-estar psicológico (a=.83) & & .79 \\
MHC9 & .64 & .79 \\
MHC1O & .60 & .83 \\
MHC11 & .44 & .79 \\
MHC12 & .62 & .78 \\
MHC13 & .68 & .61 \\
MHC14 & .61 & \\
\hline
\end{tabular}




\subsection{Correlações entre os factores}

O estudo das correlações entre os três factores da MHC-SF revelou que as dimensões factoriais estão significativamente correlacionadas, com valores que oscilam entre .49 e .62 (Quadro 9).

Quadro 9 - Correlações de Pearson entre os três factores da MHC-SF

\begin{tabular}{lcc}
\hline & $\begin{array}{c}\text { Bem-estar emocional } \\
\text { Bem-estar emocional }\end{array}$ & $\begin{array}{c}\text { Bem-estar social } \\
\mathrm{r}(\mathrm{p})\end{array}$ \\
\cline { 2 - 3 } Bem-estar social & - & \\
Bem-estar psicológico & $.49(.000)$ & - \\
\hline
\end{tabular}

\subsection{Validade convergente}

Para o estudo da validade convergente ${ }^{10}$ efectuámos correlações entre os factores da MHC-SF e as dimensões de um instrumento que mede a qualidade de vida (Kidscreen27, The KIDSCREEN Group European, 2006; traduzido e adaptado por Matos, Gaspar \& Equipa do Aventura Social e Saúde, 2006) e a nota total de uma escala que mede a satisfação com a vida (Satisfaction With Life Scale, SWLS; Diener, Emmons, Larsen \& Griffin, 1984; traduzida e adaptada por Neto, 1993).

As correlações entre os três factores da MHC-SF e as cinco dimensões da Kidscreen são positivas e a maior parte delas significativas. Oscilam entre 359 (entre o factor bem-estar psicológico da MHC-SF e a dimensão ambiente escolar da Kidscreen e .720 (entre o factor bem-estar emocional da MHC-SF e a dimensão bem-estar psicológico da Kidscreen) (Quadro 10).

Quadro 10 - Validade Convergente: correlações de Pearson entre os factores da MHC-SF e as dimensões do Kidscreen27

\begin{tabular}{lccc}
\hline & \multicolumn{3}{c}{ Factores da MHC-SF } \\
\cline { 2 - 4 } Factores da Kidscreen & $\begin{array}{c}\text { Bem-estar } \\
\text { emocional } \\
\mathrm{r}(\mathrm{p})\end{array}$ & $\begin{array}{c}\text { Bem-estar } \\
\text { social } \\
\mathrm{r}(\mathrm{p})\end{array}$ & $\begin{array}{c}\text { Bem-estar } \\
\text { psicológico } \\
\mathrm{r}(\mathrm{p})\end{array}$ \\
\cline { 2 - 4 } Bem-estar Físico & $.374(.035)$ & $.294(.103)$ & $.184(.306)$ \\
Bem-estar psicológico & $.720(.000)$ & $.447(.010)$ & $.507(.003)$ \\
Autonomia em relação aos pais & $.451(.011)$ & $.352(.052)$ & $.483(.006)$ \\
Suporte social (grupo de pares) & $.607(.000)$ & $.485(.005)$ & $.382(.031)$ \\
Ambiente Escolar & $.451(.011)$ & $.174(.350)$ & $.359(.047)$ \\
\hline
\end{tabular}

10 O estudo da validade convergente (assim como da estabilidade temporal) ainda está a decorrer, pelo que apenas se apresentam resultados preliminares para 32 adolescentes. Provavelmente com um número mais elevado de indivíduos encontraríamos valores estatisticamente mais significativos. 
As correlações entre os factores da MHC e a nota total da SWLS também são positivas e todas elas significativas, variando entre .369 para o factor bem-estar social e .811 para o bem-estar emocional (Quadro 11). A correlação entre a nota global da MHC e a nota total da SWLS é de .621 ( $p=.000)$.

Quadro 11 - Validade Convergente: correlações de Pearson entre os factores da MHC-SF e a nota total da SWLS

\begin{tabular}{lccc}
\hline & \multicolumn{3}{c}{ Factores da MHC-SF } \\
\cline { 2 - 4 } & $\begin{array}{c}\text { Bem-estar emocional } \\
\mathrm{r}(\mathrm{p})\end{array}$ & $\begin{array}{c}\text { Bem-estar social } \\
\mathrm{r}(\mathrm{p})\end{array}$ & $\begin{array}{c}\text { Bem-estar psicológico } \\
\mathrm{r}(\mathrm{p})\end{array}$ \\
\cline { 2 - 4 } $\begin{array}{l}\text { Satisfação com a vida } \\
\text { (nota da total SWLS) }\end{array}$ & $.811(.000)$ & $.369(.038)$ & $.377(.034)$ \\
\hline
\end{tabular}

\subsection{Validade divergente}

A validade divergente desta escala foi estudada através das suas correlações com o Children's Depression Inventory (CDI; Kovacs, 1992), o Children's Attribucional Style Questionnaire (CASO; Seligman et al., 1984), a Child Behavior Cheklist (CBCL; Achenbach, 1991) e a Multidiensional Anxiety Scale for Children (MASC; March et al., 1997).

A análise das correlações entre a MHC-SF e o CDI evidencia que estas são todas estatisticamente significativas, negativas e, de uma forma geral, modestas (entre -.156 e -.621) (Quadro 12).

Quadro 12 - Validade divergente: correlações de Pearson dos factores da MHC-SF com os factores e nota total do CDI

\begin{tabular}{lccc}
\hline & \multicolumn{3}{c}{ Factores da MHC-SF } \\
\cline { 2 - 4 } Factores do CDI & $\begin{array}{c}\text { Bem-estar emocional } \\
\mathrm{r}(\mathrm{p})\end{array}$ & $\begin{array}{c}\text { Bem-estar social } \\
\mathrm{r}(\mathrm{p})\end{array}$ & $\begin{array}{c}\text { Bem-estar psicológico } \\
\mathrm{r}(\mathrm{p})\end{array}$ \\
\cline { 2 - 4 } Humor Negativo & $-.461(.000)$ & $-.238(.000)$ & $-.275(.000)$ \\
Problemas Inter- & $-.361(.000)$ & $-.156(.000)$ & $-.235(.000)$ \\
pessoais & $-.369(.000)$ & $-.178(.000)$ & $-.307(.000)$ \\
Ineficácia & $-.433(.000)$ & $-.248(.000)$ & $-.307(.000)$ \\
Anedonia & $-.459(.000)$ & $-.244(.000)$ & $-.349(.000)$ \\
Auto-estima & $-.621(.000)$ & $-.344(.000)$ & $-.476(.000)$ \\
Negativa & &
\end{tabular}

Quanto às correlações existentes entre a MHC-SF e o CASO verificamos que estas são estatisticamente significativas, baixas a moderadas (de -.149 a .403), e que os factores de bem-estar correlacionam-se negativamente com o estilo atribucional 
pessimista (compósito negativo do CASO) e positivamente com o estilo atribucional optimista (compósito positivo do CASO) (Quadro 13).

Quadro 13 - Validade divergente: correlações de Pearson entre os factores da MHC-SF e os compósitos do CASO

\begin{tabular}{lccc}
\hline & \multicolumn{3}{c}{ Factores da MHC-SF } \\
\hline & $\begin{array}{c}\text { Bem-estar } \\
\text { Emocional } \\
\text { Compósitos do CASO }\end{array}$ & $\begin{array}{c}\text { Bem-estar } \\
\text { Social } \\
\text { Compósito Negativo }\end{array}$ & $\begin{array}{c}\text { Bem-estar } \\
\text { psicológico } \\
\mathrm{r}(\mathrm{p})\end{array}$ \\
\cline { 2 - 4 } Compósito Positivo & $-.307(.000)$ & $-.149(.000)$ & $-.274(.000)$ \\
\hline
\end{tabular}

Os factores de bem-estar subjectivo correlacionam-se, ainda, de uma forma negativa e estatisticamente significativa com algumas dimensões do $C B C L$, o qual mede problemas de internalização e externalização dos adolescentes, avaliados pelos pais. Nomeadamente, o factor bem-estar emocional apresenta relações significativas com a ansiedade/depressão ( $r=-.191 ; p=.001)$, isolamento/ depressão $(r=-.173 ; p=.002)$ e queixas somáticas $(r=-.209 ; p=.000)$. O factor bem-estar psicológico apresenta, também, correlações negativas e significativas com ansiedade/depressão ( $r=-.156 ; p=.005)$, isolamento/depressão $(r=-.161 ; p=.004)$, problemas sociais $(r=-.146 ; p=.009)$ e comportamento agressivo $(r=-.125 ; p=.026)$. O factor bem-estar social não se correlaciona significativamente com nenhum dos factores do CBCL (Quadro 14).

Quadro 14 - Validade divergente: correlações de Pearson entre os factores da MHC-SF e os factores do CBCL

\begin{tabular}{lccc}
\hline & \multicolumn{3}{c}{ Factores da MHC-SF } \\
\hline Factores do CBCL & $\begin{array}{c}\text { Bem-estar } \\
\text { emocional } \\
\mathrm{r}(\mathrm{p})\end{array}$ & $\begin{array}{c}\text { Bem-estar } \\
\text { social } \\
\mathrm{r}(\mathrm{p})\end{array}$ & $\begin{array}{c}\text { Bem-estar } \\
\text { psicológico } \\
\mathrm{r}(\mathrm{p})\end{array}$ \\
\cline { 2 - 4 } Ansiedade/Depressão & $-.191(.001)$ & $-.083(.137)$ & $-.156(.005)$ \\
Isolamento/Depressão & $-.173(.002)$ & $-.063(.265)$ & $-.161(.004)$ \\
Queixas Somáticas & $-.209(.000)$ & $-.076(.178)$ & $-.110(.051)$ \\
Problemas Sociais & $-.098(.080)$ & $-.024(.671)$ & $-.146(.009)$ \\
Problemas de pensamento & $-.026(.657)$ & $.066(.246)$ & $-.081(.156)$ \\
Comportamento Agressivo & $-.060(.288)$ & $.023(.679)$ & $-.125(.026)$ \\
Problemas de atenção & $-.010(.866)$ & $.091(.104)$ & $-.021(.710)$ \\
Comport. Anti-social & $.035(.538)$ & $.086(.125)$ & $-.036(.529)$ \\
\hline
\end{tabular}

Efectuaram-se correlações entre os factores da MHC-SF e os factores da MASC, a qual mede várias dimensões da ansiedade, na sua maioria com subdimensões (dimensão Sintomas Físicos - subdimensões de agitação/impaciência e queixas 
somáticas; dimensão Ansiedade Social - subdimensões de rejeição/humilhação e medo de desempenho em público; dimensão Ansiedade Separação; dimensão Evitamento do Perigo - subdimensões de perfeccionismo e ansiedade antecipatória). Obtiveram-se, na sua maioria, correlações negativas e significativas entre os factores do bem-estar subjectivo e os vários valores da ansiedade que oscilam entre -.087 (entre o bem-estar psicológico e a dimensão Ansiedade de Separação) e -.463 (entre o bem - estar emocional e a dimensão sintomas físicos). Por outro lado, encontraram-se correlações positivas e significativas, embora baixas, entre os factores do bem-estar subjectivo e a dimensão evitamento do perigo e suas respectivas subdimensões (perfeccionismo e ansiedade antecipatória), que variam entre .108 e .211 (Quadro 15).

Quadro 15 - Validade divergente: correlações de Pearson entre os factores da MHC-SF e os factores da MASC

\begin{tabular}{lccc}
\hline & \multicolumn{3}{c}{ Factores da MHC-SF } \\
\hline \multirow{2}{*}{ Factores da MASC } & $\begin{array}{c}\text { Bem-estar } \\
\text { emocional } \\
\mathrm{r}(\mathrm{p})\end{array}$ & $\begin{array}{c}\text { Bem-estar } \\
\text { social } \\
\mathrm{r}(\mathrm{p})\end{array}$ & $\begin{array}{c}\text { Bem-estar } \\
\text { psicológico } \\
\mathrm{r}(\mathrm{p})\end{array}$ \\
\cline { 2 - 4 } Sintomas Físicos & $-.463(.000)$ & $-.219(.000)$ & $-.294(.000)$ \\
$\quad$ agitação/impaciência & $-.396(.000)$ & $-.185(.000)$ & $-.250(.000)$ \\
$\quad$ queixas somáticas & $-.440(.000)$ & $-.213(.000)$ & $-.280(.000)$ \\
Ansiedade Social & $-.268(.000)$ & $-.147(.000)$ & $-.236(.000)$ \\
$\quad$ rejeição/humilhação & $-.243(.000)$ & $-.108(.002)$ & $-.198(.000)$ \\
$\quad$ medo desemp. público & $-.229(.000)$ & $-.170(.000)$ & $-.229(.000)$ \\
Ansiedade de Separação & $-.121(.000)$ & $.010(.770)$ & $-.087(.013)$ \\
Evitamento do perigo & $.168(.000)$ & $.146(.000)$ & $.211(.000)$ \\
$\quad$ Perfeccionismo & $.197(.000)$ & $.108(.002)$ & $.175(.000)$ \\
$\quad$ Ansiedade Antecipatória & $.110(.001)$ & $.134(.000)$ & $.183(.000)$ \\
\hline
\end{tabular}

4.9 Relação entre saúde mental (bem-estar subjectivo), doença mental (sintomatologia depressiva) e funcionamento (rendimento escolar e consultas de psicologia/ psiquiatria)

Através de uma correlação de Pearson verificou-se que existe uma associação negativa, moderada e significativa ( $r=-.532 ; p=.000$ ) entre saúde mental (nota total da MHC-SF) e sintomatologia depressiva (nota total do CDI).

Podemos verificar, na amostra total, que a maior parte dos adolescentes se encontra em estado de flourishing (44.7\%). Uma minoria encontra-se em estado de languishing (16.4\%) e os restantes em estado de saúde mental moderada (38.9\%). Esta tendência verifica-se em ambos os géneros. No entanto, há mais casos de 
raparigas em estado de languishing, enquanto o número de rapazes em estado de flourishing é superior $\left[x^{2}=8.112 ; p=.017\right]$. Quanto à doença mental", considerando os patamares de sintomatologia depressiva obtidos através das pontuações do CDI, a maior parte dos adolescentes encontram-se no grupo de resilientes (70.8\%) e uma minoria no grupo de deprimidos (8\%), sendo que os restantes se encontram em risco (21\%). Esta tendência verifica-se em ambos os géneros. No entanto há mais casos de rapazes resilientes, enquanto as raparigas se encontram mais em risco e deprimidas $\left[\chi^{2}=11.692 ; p=.003\right]$ (Quadro 16).

Quadro 16 - Qui-quadrado entre estados de saúde mental e doença mental (sintomatologia depressiva), em função do género

\begin{tabular}{lccc}
\hline & \multicolumn{2}{c}{ Género } & Amostra Total \\
\cline { 2 - 4 } Estados de Saúde Mental & $\begin{array}{c}\text { Masculino } \\
\mathbf{N}(\%)\end{array}$ & $\begin{array}{c}\text { Feminino } \\
\mathbf{N}(\%)\end{array}$ & $\mathbf{N}(\%)$ \\
\cline { 2 - 4 } languishing & $40(12.2 \%)$ & $98(19.1 \%)$ & $138(16.4 \%)$ \\
saúde mental moderada & $128(38.9 \%)$ & $199(38.9 \%)$ & $327(38.9 \%)$ \\
flourishing & $161(48.9 \%)$ & $215(42 \%)$ & $376(44.7 \%)$ \\
$\chi^{2}=8.112 ; \mathrm{p}=.017$ & & & \\
\hline Grupos de doença mental & & & $612(70.8 \%)$ \\
Resilientes & $256(77.1 \%)$ & $356(66.8 \%)$ & $184(21.3 \%)$ \\
Risco & $59(17.8 \%)$ & $125(23.5 \%)$ & $69(8 \%)$ \\
Deprimidos & $17(5.1 \%)$ & $52(9.8 \%)$ & \\
$\chi^{2}=11.692 ; p=.003$ & & & \\
\hline
\end{tabular}

Através de uma análise de qui-quadrado, verificou-se que o estado de saúde mental diverge consoante a gravidade da sintomatologia depressiva, sendo essa diferença estatisticamente significativa $\left[\chi^{2}=109.084 ; p=.000\right]$. Assim, e de acordo com o quadro 17, a maior parte dos adolescentes do grupo de resilientes apresenta um estado de flourishing (50.4\%), seguindo-se-Ihe o estado de saúde mental moderada (38.8\%) e o estado de languishing (10.8\%). Por outro lado, a maior parte dos adolescentes em risco de depressão evidencia um estado de saúde mental moderada (48.6\%), seguindo-se-lhe o estado de flourishing (31.2\%), e o estado de languishing (20.2\%). Por fim, a maior parte dos adolescentes deprimidos apresenta um estado de languishing (57.6\%), seguindo-se-lhe o estado de saúde mental moderada (24.2\%), e o estado de flourishing (18.2\%).

\footnotetext{
11 À semelhança do que os autores Arnarson \& Craighead (2009) efectuaram no seu estudo, foram criados três grupos a partir das pontuações obtidas no CDI. Assim, o grupo de resilientes pontua entre o e 15 (abaixo do percentil 70), o grupo de risco entre 15 e 21 (percentis 70-90) e o grupo de deprimidos tem pontuações superiores a 22 (acima do percentil 90). Os grupos que estes autores consideram parecem estar de acordo com uma visão de continuum da doença mental e permitem, para além da identificação de adolescentes com sintomatologia depressiva, fazer a distinção entre os que estão em risco e os que são resilientes, a qual é importante para o estudo da problemática da prevenção.
} 
Podemos ainda verificar que $3.4 \%$ dos adolescentes em flourishing, $5 \%$ dos adolescentes em saúde mental moderada e $28 \%$ dos que estão em languishing, têm sintomatologia depressiva. Isto significa que, comparativamente com os adolescentes que estão em flourishing, os adolescentes em saúde mental moderada têm uma probabilidade de 1.5 vezes superior de ter sintomatologia depressiva, enquanto os que estão em languishing têm uma probabilidade de 8.4 vezes maior de desenvolver problemas depressivos.

Quadro 17- Qui-quadrado entre os grupos de saúde mental e os grupos de doença mental

\begin{tabular}{lccc}
\hline & \multicolumn{3}{c}{ Grupos do CDI - doença mental } \\
\cline { 2 - 4 } Estados de Saúde Mental & $\begin{array}{c}\text { Resilientes } \\
\mathrm{N}(\%)\end{array}$ & $\begin{array}{c}\text { Riscos } \\
\mathrm{N}(\%)\end{array}$ & $\begin{array}{c}\text { Deprimidos } \\
\mathrm{N}(\%)\end{array}$ \\
\cline { 2 - 4 } languishing & $61(10.8 \%)$ & $35(20.2 \%)$ & $38(57.6 \%)$ \\
saúde mental moderada & $220(38.8 \%)$ & $84(48.6 \%)$ & $16(24.2 \%)$ \\
flourishing & $286(50.4 \%)$ & $54(31.2 \%)$ & $12(18.2 \%)$ \\
$\chi^{2}=109.084 ; p=.000$ & & & \\
\hline
\end{tabular}

Relativamente às relações existentes entre a MHC-SF e outros indicadores de funcionamento, para o Rendimento Escolar, foram identificadas diferenças estatisticamente significativas entre os diferentes estados de saúde mental $\left[\chi^{2}=\right.$ 22.644; $p=.004$ ]. Especificamente, os alunos com saúde mental moderada são aqueles que apresentam maiores percentagens de rendimento escolar insuficiente (50\%) e suficiente (43.3\%); os adolescentes em flourishing são aqueles que mais revelam rendimentos escolares satisfatório (44.3\%), bom (50.4\%) e muito bom (60\%) (Quadro 18).

Quadro 18 - Qui-quadrado entre os estados de saúde mental e o Rendimento Escolar

\begin{tabular}{lccccc}
\hline & \multicolumn{5}{c}{ Rendimento Escolar } \\
\cline { 2 - 6 } $\begin{array}{l}\text { Estados de } \\
\text { Saúde Mental }\end{array}$ & $\begin{array}{c}\text { Insuficiente } \\
\mathrm{N}(\%)\end{array}$ & $\begin{array}{c}\text { Suficiente } \\
\mathrm{N}(\%)\end{array}$ & $\begin{array}{c}\text { Satisfatório } \\
\mathrm{N}(\%)\end{array}$ & $\begin{array}{c}\text { Bom } \\
\mathrm{N}(\%)\end{array}$ & $\begin{array}{c}\text { MuitoBom } \\
\mathrm{N}(\%)\end{array}$ \\
\cline { 2 - 6 } Languishing & $7(29.2 \%)$ & $28(22 \%)$ & $65(16.8 \%)$ & $33(13.9 \%)$ & $3(5.5 \%)$ \\
saúde mental & $12(50 \%)$ & $55(43.3 \%)$ & $150(38.9 \%)$ & $85(35.7 \%)$ & $19(34.5 \%)$ \\
moderada & $5(20.8 \%)$ & $44(34.6 \%)$ & $171(44.3 \%)$ & $120(50.4 \%)$ & $33(60 \%)$ \\
Flourishing & & & & & \\
$\chi^{2}=22.644 ; p=.004$ & & &
\end{tabular}

Atendendo agora ao facto de o adolescente ter, ou já ter tido, consultas de psicologia ou psiquiatria, verifica-se que existem diferenças estatisticamente significativas entre os diferentes estados de saúde mental $\left[x^{2}=8.923 ; p=.012\right]$. Os indivíduos em languishing apresentam percentagens mais elevadas de consultas de psicologia e psiquiatria (38\%) do que os que têm saúde mental moderada $(25.8 \%$ ) ou dos que estão em flourishing (25.3\%) (Quadro 19). 
Quadro 19 - Qui-quadrado entre os estados de saúde mental e consultas de psicologia/ psiquiatria

\section{languishing}

saúde mental moderada

flourishing

$\chi^{2}=8.923 ; p=.012$
Consultas de psicologia/psiquiatria

\begin{tabular}{cc} 
Sim & Não \\
$\mathbf{N}(\%)$ & $\mathbf{N}(\%)$ \\
\hline $52(38 \%)$ & $85(62 \%)$ \\
$84(25.8 \%)$ & $242(74.2 \%)$ \\
$94(25.3 \%)$ & $278(74.7 \%)$ \\
$(\mathrm{N}=230)$ & $(\mathrm{N}=605)$
\end{tabular}

\section{Discussão}

Relativamente aos dados descritivos da MHC-SF, debruçar-nos-emos sobre a distribuição das frequências das respostas dadas aos itens e das categorias dos estados de saúde mental, bem como, dos factores da escala, tendo em conta a amostra total e em função do género e da idade.

Através da análise das médias das frequências das respostas dadas aos vários itens da MHC-SF, encontraram-se pontuações mais elevadas no factor bem-estar emocional, mais baixas no factor bem-estar social, situando-se o factor bem-estar psicológico em valores intermédios. Os adolescentes referiram ter vivenciado quase todos os dias os três itens do bem-estar emocional (interesse, felicidade e satisfação). Experimentaram, ainda, os seis itens do bem-estar psicológico duas a três vezes por semana. Relativamente ao bem-estar social, encontrou-se o seguinte: uma a duas vezes por semana, sentiram que tinham algo a contribuir para a sociedade (contribuição social) e que esta tinha uma organização que fazia sentido para eles (coerência social) e que tinha um potencial positivo de evolução (actualização social); duas a três vezes por semana, sentiram que pertenciam a uma comunidade (integração social) e que as pessoas são essencialmente boas, confiáveis e gentis (aceitação social). Keyes (2005b), num estudo com 1200 adolescentes, dos 12 aos 18 anos de idade, encontrou médias das frequências de resposta semelhantes nos factores bem-estar emocional e bem-estar psicológico, as quais, por sua vez, são mais baixas do que a média do factor bem-estar social. Encontrou, também, que os adolescentes vivenciaram os itens do bem-estar emocional e psicológico quase todos os dias, sendo que os itens do bem-estar social foram assinalados com frequências que variavam de duas a três vezes por semana (integração social e sentido de contribuição social) até uma vez por semana (crescimento social, aceitação social e coerência social). Podemos concluir, comparando a presente investigação com a de Keyes 
(2005b), que os adolescentes dos dois estudos assinalaram ter vivido os itens do bem-estar emocional com bastante frequência, ou seja, sentiam-se, quase todos os dias, interessados pela vida, felizes e satisfeitos. Os adolescentes Portugueses registaram menos frequentemente vivências de bem-estar psicológico do que os adolescentes Americanos. No entanto, os adolescentes da amostra Americana atingiram frequências mais baixas do que os da amostra Portuguesa, especialmente nalguns itens do bem-estar social, nomeadamente de crescimento, aceitação e coerência social.

Relativamente à frequência por categorias de estado de saúde mental obteve-se que a maior parte dos adolescentes (44.7\%) estão em flourishing, 38.9\% têm saúde mental moderada e $16.4 \%$ estão em languishing. Keyes (2009) obteve que a maioria dos adolescentes tinha saúde mental moderada (56\%) e encontrou valores mais baixos para oflourishing (38\%) e para o languishing (9\%).

Observaram-se diferenças estatisticamente significativas entre géneros, em todos os domínios do bem-estar subjectivo, sendo que os rapazes apresentam valores mais elevados que as raparigas. Verificou-se também que há mais casos de raparigas em estado de languishing e maior número de rapazes em estado de flourishing. Keyes (2002) refere igualmente, mas num estudo efectuado com adultos, que o flourishing é mais prevalente nos homens do que nas mulheres.

Encontrou-se, na presente amostra de adolescentes, dos 12 aos 16 anos, que os adolescentes mais novos, de 12 anos, apresentam valores mais altos no factor bem-estar emocional do que os mais velhos, de 16 anos. Obteve-se, ainda, que existe uma correlação negativa entre o total da $M H C$ e a idade $(r=-.088 ; p=.011)$ e que os adolescentes do ensino secundário estão menos em flourishing (com um decréscimo de $3.3 \%$ ) do que os mais novos, do $2^{\circ}$ e $3^{\circ}$ ciclos. Keyes (2009) encontrou também que a saúde mental diminui dos 12 aos 18 anos ( $r=-.07$; $p<.02)$ e que se verifica um decréscimo da prevalência do flourishing (de $9 \%$, entre o grupo dos 12 aos 14 anos - middle school e o grupo dos 15 aos 18 anos - high school). A prevalência do estado de languishing mantém-se nos dois grupos etários, quer na amostra Americana, quer na amostra Portuguesa.

Neste estudo efectuou-se uma Análise Factorial Exploratória para averiguar os componentes principais da MHC-SF que Keyes (2009) sugeriu baseando-se na teoria e corroborou posteriormente através de Análise Factorial Confirmatória.

A solução factorial encontrada é constituída por três componentes principais que explicam $61,48 \%$ da variância. Os factores encontrados, bem-estar emocional, bem-estar social e bem-estar psicológico, vão ao encontro da estrutura factorial sugerida por Keyes (2005a). 
O factor bem-estar emocional é constituído pelos itens 1, 2, 3, 10 e 14; o factor bem-estar social pelos itens 4, 5, 6, 7 e 8; e o factor bem-estar psicológico pelos itens 9, 11, 12 e 13 .

De acordo com a literatura consultada (Hair et al., 2006), todas as correlações item-factor acima de 50 podem ser consideradas como um bom sinal de consistência interna. Na generalidade (12 dos 14 itens da escala) apresentam resultados que excedem esse valor, o que significa que todos os itens de uma dimensão avaliam o mesmo.

Quanto aos resultados das comunalidades, quase todos os itens (à excepção do item 5) atingem valores aceitáveis acima de .50 (Hair et al. 2006).

No que diz respeito aos pesos dos itens que constituem os factores, e admitindo que abaixo de .30 um item deverá ser removido da escala (Blunch, 2008; Brown, 2006; Hair et al., 2006), verificamos que todos os itens apresentam pesos factoriais aceitáveis nos respectivos factores. Quanto ao item 9, poder-se-ia ponderar a sua eliminação da MHC-SF dado que este item satura nos factores 2 e 3 com o mesmo valor (existência de um cross-loading) e no factor 1 com uma diferença inferior a .10. Contudo, Worthington e Whittaker (2006) aconselham alguma prudência na utilização deste critério para justificar a eliminação de itens até que seja encontrada uma solução final. Além disso, apesar de se manter o cross-loading, o item 9 satura significativamente no factor onde é suposto pertencer (bem-estar psicológico). Para além disso, se for analisado o conteúdo do item "(...) que gostavas da maior parte das características da tua personalidade" não restam dúvidas que este é relativo a uma dimensão de bem-estar psicológico, como aliás, é sugerido por Keyes. Assim, sugere-se que este item seja mantido nesta versão da escala.

Ainda relativamente à saturação dos itens nos factores, os itens 10 [(...) que geriste bem as responsabilidades da tua vida diária] e 14 [(...) que a tua vida tem uma direcção ou significado], na amostra do presente estudo, saturam no factor bem-estar emocional em vez de no factor bem-estar psicológico. No entanto, tendo em conta o seu conteúdo, bem como a sugestão do autor original da MHC-SF, estes itens parecem pertencer, claramente, ao factor bem-estar psicológico. Acresce que, na presente amostra, embora estes itens saturem mais no bem-estar emocional, saturam também no factor bem-estar psicológico.

Os valores do alpha de Cronbach encontrados para os factores bem-estar emocional $(\mathrm{a}=.847)$, bem-estar social $(\mathrm{a}=.803)$ e bem-estar psicológico $(\mathrm{a}=.829)$ traduzem uma boa consistência interna (Hill \& Hill, 2000; Hair et al., 2006) e são semelhantes aos encontrados pelo autor da escala (respectivamente, $\mathrm{a}=.84$, $\mathrm{a}=.80 \mathrm{e} \mathrm{a}=.78$ ). Relativamente ao item 5 (Integração, factor bem-estar social), verifica-se que, quando este é retirado, aumenta (de .80 para .81) o alpha de Cronbach do factor em que 
se insere (bem-estar social). A este propósito, salienta-se que este item apresenta também uma comunalidade e uma correlação item-factor baixas. Apesar destes valores menos favoráveis obtidos para o item 5 , este foi mantido provisoriamente na escala e sugere-se que futuros estudos - com amostra maiores e análises factoriais confirmatórias - ajudem a determinar a sua manutenção ou remoção.

As correlações entre factores são adequadas (nem muito baixas, nem demasiado altas), variando entre.49 e .62. Keyes (2009) encontrou valores semelhantes (entre .57 e .71$)$.

Relativamente ao estudo da validade convergente e divergente, eram esperadas relações mais fortes da MHC-SF com medidas semelhantes (Kidscreen27 que mede Qualidade de Vida e SWLS que avalia Satisfação com a Vida), do que com medidas de constructos diferentes (CDI, CASO, MASC e CBCL). Os dados obtidos revelam-nos que a MHC-SF a presenta correlações positivas com outras medidas de saúde mental (qualidade de vida e satisfação com a vida) e negativas com indicadores de doença mental (sintomatologia depressiva, estilo atribucional negativo, sintomatologia ansiosa e problemas de internalização e de externalização), sendo as primeiras mais fortes do que as últimas. Estes resultados vão no sentido previsto, o que pode indicar que a MHC-SF é uma medida de saúde mental.

A MHC-SF estabelece uma relação positiva e moderada com o estilo atribucional optimista do CASO, tal como era previsto. No entanto, ao invés do esperado, as correlações com o factor da MASC, Evitamento do Perigo (e respectivas dimensões Ansiedade Antecipatória e Perfeccionismo), também são positivas, embora baixas. Este resultado sugere que pode ser adaptativo evitar situações perigosas, antecipando a ameaça, agindo correctamente com os outros e evitando cometer erros.

Uma análise mais detalhada das correlações existentes entre a MHC-SF e o CDI indica que estas são todas negativas e estatisticamente significativas, sendo que um maior número de sintomas de flourishing (nomeadamente de bem-estar emocional, social e psicológico) está modestamente correlacionado com um menor número de sintomas depressivos (especificamente, humor negativo, problemas interpessoais, ineficácia, anedonia e auto-estima negativa). Os factores bem-estar emocional da MHC-SF e o Humor Negativo do CDI são aqueles que mais se correlacionam. $\mathrm{O}$ facto de se tratarem de correlações modestas pode revelar que o constructo de saúde mental não se resume apenas à ausência de doença mental.

Keyes (2002), numa revisão de estudos, refere que estes também têm encontrado correlações negativas e moderadas entre medidas de sintomas de doença mental, nomeadamente depressão e medidas de bem-estar subjectivo. As medidas de bem-estar psicológico apresentam em média correlações de -.51 com o Inventário de Depressão de Zung e de -.55 com a Escala Epidemiological Studies Depression 
(CESD). O bem-estar emocional também se correlacionou entre -.40 e -.50 com escalas que medem sintomatologia depressiva.

Foram encontradas, também, correlações negativas, embora baixas, dos factores bem-estar emocional e bem-estar psicológico com alguns factores do CBCL, 152 (indicadores de problemas de internalização e externalização). Keyes (2009) obteve que o estado de saúde mental (i.e., languishing, saúde mental moderada ou flourishing) se associa com problemas de comportamento (à medida que a saúde mental aumenta, os problemas de comportamento diminuem). No presente estudo, encontrámos também correlações negativas entre o bem-estar psicológico da MHC-SF e dois factores do CBCL, da esfera social (Problemas Sociais e Comportamento Agressivo).

Quando cruzamos as categorias de doença mental (neste caso, medidas pelo CDI) com as de saúde mental constatamos que a maioria dos adolescentes resilientes se encontra em estado de flourishing, aqueles que estão em risco para deprimirem apresentam sobretudo saúde mental moderada, enquanto a maior parte dos adolescentes deprimidos se encontra num estado de languishing. Encontramos ainda que os adolescentes em flourishing são os que têm percentagens mais baixas de queixas depressivas (3.4\%), aumentando progressivamente a probabilidade de surgir sintomatologia depressiva nos adolescentes com saúde mental moderada e nos adolescentes em languishing. Keyes ${ }^{12}$ (2009) encontrou resultados semeIhantes: $4.9 \%$ dos adolescentes em flourishing tinham sintomatologia depressiva, aumentando o risco de desenvolver problemas depressivos 3.5 vezes nos adolescentes com saúde mental moderada e 10.5 vezes nos que estão em languishing. Os nossos resultados e os de Keyes vão no sentido esperado, sugerindo que a saúde mental, nomeadamente o flourishing, se relaciona inversamente com sintomatologia depressiva.

Quanto à relação entre estado de saúde mental e funcionamento escolar, encontramos que são os adolescentes em flourishing que apresentam melhor aproveitamento académico. Keyes (2009) ao estudar a relação entre os estados de saúde mental e alguns indicadores de funcionamento, nomeadamente, a integração escolar (sentimento de felicidade, segurança e proximidade com os outros na escola), encontrou, também, uma relação positiva entre eles.

Relativamente a outro indicador de funcionamento, frequência de consultas de psicologia/psiquiatria, obteve-se que são os adolescentes em languishing que apresentam percentagens mais elevadas, seguindo-se os que estão em saúde

\footnotetext{
12 Para formar as categorias de doença mental, Keyes considerou como ponto de corte a pontuação de 6 do CDI (forma abreviada), constituindo um grupo de adolescentes com problemas depressivos e outro grupo sem este tipo de problemas.
} 
mental moderada e os que estão em flourishing. Mais uma vez, os resultados apontam no sentido do flourishing se associar com bom funcionamento.

A evidência empírica mostra que percepções de bem-estar subjectivo se relacionam com a adaptação do indivíduo. Assim, quanto mais em flourishing o adolescente estiver, maior será a sua tendência para adoptar comportamentos adaptativos e, pelo contrário, menor será a probabilidade de deprimir (Keyes, 2002). Os dados do presente estudo, confirmam a existência de uma relação entre flourishing e adaptação.

No entanto, a presente investigação apresenta algumas fragilidades no que se refere à constituição da amostra, pois esta não se encontra equilibrada quanto à distribuição por géneros e por idade. É constituída por mais raparigas do que rapazes e tem uma predominância dos 12 e 15 anos de idade. Será importante em futuras investigações, para além de aumentar o número de sujeitos que constituem a amostra, torná-la mais homogénea em termos destas variáveis sóciodemográficas. Também será muito importante, em amostras mais representativas, replicar os dados desta investigação e efectuar uma análise factorial confirmatória. A estrutura factorial da escala e os itens que a constituem deverão ser repensados após a realização destes estudos, pelo que, no presente estádio da investigação, seja prudente não remover itens da escala, mantendo-se, para já, o seu formato original.

Os resultados obtidos revelam as potencialidades do instrumento em estudo, a MHC-SF. Podemos afirmar que a adaptação da escala à população portuguesa, neste estudo exploratório, revela boas qualidades psicométricas. A MHC-SF possui uma boa consistência interna e os dados relativos à validade de constructo, nomeadamente validade convergente e divergente, mostram que esta escala poder ser uma boa medida de bem-estar subjectivo.

Sugerimos, tal como Keyes (2005), que a aplicação da MHC-SF não se deve restringir à população geral, podendo ser relevante utilizá-la em populações clínicas.

Quanto às implicações que o estudo do bem-estar subjectivo poderá ter nos vários níveis de intervenção psicológica, desde a protecção de saúde mental ao tratamento da doença mental, gostaríamos ainda de tecer algumas considerações. Os resultados deste estudo sugerem que se deve investir na protecção e promoção da saúde mental. Keyes (2010) salienta que aumentar o nível de saúde mental, faz diminuir o risco de doença mental futura, sendo este aspecto muito importante para a protecção e promoção de saúde mental. As investigações têm validado que o bem-estar subjectivo é um constructo multidimensional, sendo que deverá ser promovido em vários domínios - emocional, psicológico e social. Devido ao défice de bem-estar social, percepcionado pelos adolescentes Portugueses, este domínio 
deverá ser especialmente focado na promoção do bem - estar subjectivo. Deverá ainda ser equacionada a necessidade de estratégias de promoção do bem-estar subjectivo que sejam sensiveis a diferenças de géneros. Relativamente à intervenção na psicopatologia, para além de se investir no tratamento, será também importante promover componentes de saúde mental, nomeadamente o bem - estar subjectivo.

\section{Referências bibliográficas}

Achenbach, T. M. (I991a). Integrative guide for the 1991 CBCLI4-18, YSR, and TRF Profiles. Burlington: University of Vermont, Department of Psychiatry.

Arnarson, E. O. \& Craighead, W. E. (2009). Prevention of depression among Iceland adolescents. Behaviour Research and Therapy, 47, 577-585.

Blunch, N. (2008). Introduction to structural equation modelling using SPSS and AMOS. London: Sage.

Brown, T. (2006). Confirmatory factor analysis for applied research. New York: The Guilford Press.

Duckworth, A. L., Steen, T. A., Seligman, M. E. (2005). Positive Psychology in Clinical Practice. Annual Review of Clinical Psychology, 1, 629-651.

Hair, J. F., Black, W., Babin, B., Anderson, R. \& Tatham, R. (2006). Multivariate Data Analysis ( $6^{\text {th }}$ ed). New Jersey: Pearson Education, Inc..

Hill, M. \& Hill, A. (2006). Investigação por questionário. Lisboa: Edições Sílabo.

Keyes, C. L. M. (2002). The mental health continuum: from languishing to flourishing in life. Journal of Health and Social Behavior, 43 (2), 207-222.

Keyes, C. L. M. (2003). Complete Mental Health: an agenda for the 21sts. century. In C.L.M. Keyes \& J. Haidt (Eds.). Flourishing: positive psychology and the life well-lived (pp. 293-312). Washington, DC: American Psychological Association.

Keyes, C. L. M. (2005a). Mental illness and/or mental health? Investigating axioms of the complete state model of health. Journal of Counsulting and Clinical Psychology, 73 (3), 539-548.

Keyes, C. L. M. (2005b). The Subjective well-being of American's youth:Toward a comprehensive assessment. Adolescent and Family Health, 4, 3-11.

Keyes, C. L. M. (2006). Subjective well-being in mental health and human development research worldwide: an introduction. Social Indicators Research, 77, 1-10.

Keyes, C. L. M. (2007). Promoting and protecting mental health as flourishing: a complementary strategy for improving national mental health. American Psychologist, 62 (2), 98-108.

Keyes, C. L. M. (2009). The Nature and Importance of Positive Mental Health in America's Adolescents. In Gilman, R., Huerbner, E. S. \& Furlong, M. J. (Eds.). Handbook of Positive Psychology in Schools (pp. 9-23). New York: Routledge.

Keyes, C. L. M. (2010). Change in Level of Positive Mental Health as a Predictor of Future Risk of Mental Illness. American Journal of Public Health, 100 (12), 2366-2371.

Keyes, C. L. M., Shmotkin, D. \& Ryff, C. D. (2002). Optimizing well-being: The empirical encounter of two traditions. Journal of Personality and Social Psychology, 82, 1007-1022.

Kovacs, M. (1992). Children's Depression Inventory (CDI). New York: Multi-health Systems, Inc. March, J. S., Parker, J. D. A., Sullivam, L., Stallings, P. \& Conners, C. K. (1997). The Multidimensional Anxiety Scale for Children (MASC): factor, structure, reliability and validity. Journal American Academy of Child and Adolescent Psychiatry, 36 (4), 554-565. 
Matos, M. G., Gaspar, T. \& Equipa do Aventura Social e Saúde (2006). The KIDSCREEN Group European (2006). The KIDSCREEN Questionnaires: quality of life questionnaires for Children and Adolescents. Pabst Science Publishers, Germany. Consultado a 4 de Novembro 2008, em http://www.fmh.utl.pt/aventurasocial/

Neto, F. (1993). The Satisfaction with life scale: psychometrics properties in an adolescent sample. Journal of Youth and Adolescence, 22 (2), 125-134.

Seligman, M. E. P. \& Csikszentmihalyi, M. (2000). Positive psychology: an introduction. American Psychologist, 55 (1), 5-14.

Seligman, M.E.P., Peterson, C., Kaslow, N.J., Tanenbaum, R.L., Alloy, L.B. \& Abramsom, L.Y. (1984). Attributional style and depressive symptoms among children. Journal of Abnormal Psychology, 93, 235-238.

Simões, M. R. (1994). Investigação no âmbito da aferição nacional dos Testes das Matrizes coloridas de Raven (M.P.C.R.). Dissertação de Doutoramento, Faculdade de Psicologia e de Ciências da Educação, Universidade de Coimbra.

Suldo, S. M. \& Shaffer, E. J. (2008). Looking behind psychopathology: the dual factor model of mental health in youth. School Psychology Review, 37 (1), 52-68.

The KIDSCREEN Group European (2006). The KIDSCREEN Questionnaires: quality of life questionnaires for children and adolescents. Pabst Science Publishers, Germany.

World Health Organization (2004). Promoting mental health: concepts, emerging evidence, practice (summary Report). Geneva: Author.

Worthington, R. \& Whittaker, T. (2006). Scale development research. A content analysis and recommendations of best practice. The Counseling Psychologist, 34 (6), 806-838.

\section{"Preliminary psychometric study of the Mental Health Continuum - Short Form - for youth, in a sample of Portuguese adolescents"}

The definition and assessment of mental health imply not only the absence of mental illness as also the existence of subjective well-being (WHO, 2004). Keyes (2002) proposed a self-report scale, The Mental Health Continuum - Short Form - for youth (MHC-SF), in order to assess a continuum of mental health and to identify categorical diagnoses (flourisnhing, moderate mental health and languisinhg) of mental health. In this study, we translated and adapted this scale to a sample of Portuguese adolescents. It was developed a psychometric study of the MHC-SF throught the exploration of factor structure, internal consistency analysis, convergent and divergent validity. This scale revealed good psychometric properties and it seems indicated for detecting categories of mental health in adolescents. MHC - SF can also be used to identify dimensions of well-being (psychological, emotional and social) that are important in prevention and treatment of mental illness, as in protection and promotion of mental health.

KEY-WORDS: Psychometric study, States of mental health, Subjective well-being, Mental illness, Mental health promotion. 


\section{Étude psychométrique préliminaire du Mental Health Continuum - Short Form - for youth, dans un échantillon d'adolescents Portugais}

La définition et l'évaluation de la santé mentale présupposent non seulement l'absence de maladie mentale, mais aussi l'existence de bien-être subjectif (WHO, 2004). Keyes (2002) a proposé une échelle d'auto-réponse, Mental Health Continuum - Short Form - for youth (MHC-SF), afin d'évaluer le continuum de la santé mentale et d'identifier les diagnostics catégorielles (flourishing, santé mentale modérée, languishing). Dans cette étude, on a traduit et adapté cette échelle à un échantillon d'adolescents Portugais. On a développé une étude psychométrique de la MHC-SF par l'exploitation de sa structure factorielle, par l'analyse de la consistance interne, par la validité convergente et divergente. Cette échelle a révélé de bonnes propriétés psychométriques et elle nous semble apte à détecter des catégories de santé mentale chez les l'adolescents. L'échelle peut encore être utilisée pour identifier les dimensions du bien-être (psychologique, émotionnel et social) lesquelles sont importantes pour la prévention et le traitement de la maladie mentale et, aussi, pour la protection et la promotion de la santé mentale.

MOTS-CLÉS: Étude psychométrique, État de la santé mentale, Bien-être subjectif, Maladie mentale, Promotion de la santé mentale. 